\title{
Synthesis of Octyl Dihydrocaffeate and Its Transesterification with Tricaprylin Catalyzed by Candida antarctica Lipase
}

\author{
Vivian Feddern, ${ }^{*}$ Zhiyong Yang, Xuebing Xu, Eliana Badiale-Furlong, and Leonor Almeida de Souza-Soares \\ EMBRAPA, BR 153, Km 110, Concórdia 89700-000, Brazil
}

ABSTRACT: This work aimed at producing a phenolic ester from dihydrocaffeic acid (DHCA), besides carrying out transesterification reactions of this ester with tricaprylin. The esterification reaction was performed in two ratios (1:1 and $1: 3$ DHCA:octanol), and the transesterification was done in four ratios (1:1, 1:2, 1:5, and 1:10) between the produced ester and tricaprylin. In the last, a Central Composite Rotatable Design was employed, varying the amount of enzyme (1.6-18.4\%), reaction time $(9.9-35.1 \mathrm{~h})$, and temperature $\left(43.2-76.8^{\circ} \mathrm{C}\right)$ on reagent consumption percentage. Novozym 435 was the catalyst in all reactions. The highest ester yield (50\%) occurred in 8 days. In transesterification reactions, higher consumption of the produced ester was achieved at ratios 1:5 and 1:10, obtaining, respectively, $29.6 \%$ and $21.1 \%$ of octyl dihydrocaffeate residual, in $24 \mathrm{~h}$. At higher temperatures and time above $26 \mathrm{~h}$, there was less octyl dihydrocaffeate residual (18.7\%). Three different phenolic compounds were identified.

\section{INTRODUCTION}

Aromatic esters of hydroxycinnamic acid derivatives are found in natural sources such as bee propolis and plants and have been found to have antioxidant, anticancer, anti-HIV, and antimicrobial activities. ${ }^{1}$ Phenolic esters derive from cinnamic acids, with the hydroxycinnamic acids being the major subgroup of phenolic compounds. Dihydrocaffeic acid (DHCA), a metabolite of caffeic acid, can be found in many fruits, vegetables, and herbs, for example, coffee, artichoke, pear, basil, thyme, oregano, and apple. It has been reported that caffeic acid is also able to protect skin cells when exposed to ultraviolet (UV) radiation. ${ }^{2-6}$

To date, designer bioactive compounds have already been successfully synthesized through enzymatic modification, using a host of bioactive structures and acyl groups of varying chain lengths and unsaturation. ${ }^{7,8}$ Lipases from many sources were used to catalyze both esterification and transesterification reactions of these compounds, with Novozym 435 (C. antarctica) being shown as extremely robust and among the most effective and commonly used enzymes, although it is a nonregiospecific one. With regards to the reaction system, the synthesis of bioactive compounds has been carried out in organic solvent, solvent-free systems, as well as in novel media, such as room temperature ionic liquids. ${ }^{9}$ In all of these systems, the major challenge lies in bringing together the substrates (i.e., hydrophilic flavonoid and hydrophobic long chain fatty acids) with widely differing polarities. Most often, good contact between the substrates and lipase requires at least some compromise during solvent selection: tert-butanol, acetone, and even cosolvent systems such as octane/2-butanone have been shown to work. Solvent-free systems seem most effective when the substrates in question are fluid and mass transfer limitations reduced. ${ }^{10}$

Esterification of phenolic acids (including various hydroxycinnamic derivatives) with aliphatic alcohols such as methanol and octanol catalyzed by lipase has been reported. For instance, esterification efficiency with Candida antarctica lipase of phenolic acids is strongly dependent on the different characteristics of arylaliphatic substrates like glycolipids, cinnamic acids, and so on, suggesting that hydroxycinnamic acid access to the active site of the enzyme is hindered due to reduced flexibility of the acyl residue. ${ }^{11}$ Because of the relative polar properties, important efforts have been made to increase the hydrophobicity of phenolic compounds and therefore produce amphiphilic molecules of industrial value. Thus, esters of dihydrocaffeic acids, as well as alkyl coumarates and ferulates, have been widely reported as antioxidants in food, cosmetic, and pharmaceutical formulations. ${ }^{7,12}$

Lipophilization of phenolic acids with fatty alcohols can be used as a tool to alter the phenolics solubility in oil-based formulas and emulsions. These new amphiphilic antioxidant molecules could be used as multifunctional emulsifiers in the food, cosmetic, and pharmaceutical industries, as they should conserve their other functional properties such as UVA and UVB filters, antimicrobial, antiviral, bacteriostatic, etc. ${ }^{3}$

Medium-chain triacylglycerol (MCT), as tricaprylin, has primarily fatty acids that contain chain lengths of 6-12 carbons. Because of their saturation, they are stable to oxidation. They have low viscosity and melting points and are generally liquid at room temperature. Their smaller molecular size and relatively high solubility in water contribute to different digestive and absorptive properties, as compared to long-chain TAG. ${ }^{13}$

The aim of the present work was to synthesize phenolic ester from dihydrocaffeic acid and octanol from the assumption that the phenolic ester has a better compatibility with the glycerides than dihydrocaffeic acid, besides better solubility. The work also aimed at studying transesterification reactions catalyzed by fungal lipase, from the produced ester and tricaprylin.

Received: January 6, 2011

Accepted: May 12, 2011

Revised: $\quad$ May 6, 2011

Published: May 12, 2011 


\section{EXPERIMENTAL SECTION}

Material. Dihydrocaffeic acid (DHCA) or 3,4-dihydroxyhydrocinnamic acid and 1-octanol (Fluka) were obtained from Sigma (St. Louis, MO). Caprylic acid was purchased from Riedel-de Haën (Hannover, Germany). Novozym 435, an immobilized lipase from Candida antarctica, was donated by Novozymes A/S (Bagsværd, Denmark). Tricaprylin was produced in the Agrobiotechnology laboratory at the University of Århus from caprylic acid and glycerol. All chemicals and solvents were of analytical grade.

Ester Production. First, two different molar ratios (1:1 and 1:3 DHCA:octanol) were studied for ester production using $10 \%$ enzyme (Novozym 435, a lipase from C. antarctica), $10 \%$ of molecular sieves ( $3 \AA$ A , from Sigma-Aldrich, Broendby, Denmark), both calculated in relation to substrates (DHCA and octanol). The temperature was maintained at $60^{\circ} \mathrm{C}$ by water bath under magnetic stirring at $300 \mathrm{rpm}$. tert-Butanol $(500 \mathrm{~mL}$ for $2 \mathrm{~g}$ of DHCA and $4.33 \mathrm{~g}$ of octanol) was used as solvent to be particularly effective for relatively hydrophilic substrates. ${ }^{1}$ To evaluate the esterification rate, a solution sample $(10 \mu \mathrm{L})$ was periodically withdrawn and subjected to HPCL analysis. Further, molecular sieves and enzyme were removed by filtration in Whatman filter paper $(42.5 \mathrm{~mm} \varnothing)$, followed by solvent evaporation at $80^{\circ} \mathrm{C}$.

Ester Purification. The purified ester was obtained after extraction with hexane and $\mathrm{NaCl}$ solution (1\%) several times until the unreacted DHCA was removed. After that, ester was washed several times with Milli-Q water until octanol was totally removed. Thus, the octyl dihydrocaffeate ester was obtained and utilized this way for transesterification reactions, according to Yang et al. ${ }^{14}$

Transesterification Reaction. The transesterification reactions were carried out without solvent in water-jacket reactors with magnetic stirring at $60^{\circ} \mathrm{C}$ and $10 \%$ enzyme (wt \%, based on total reagents) in different molar ratios (1:1, 1:3, 1:5, and 1:10) with octyl dihydrocaffeate kept constant while tricaprylin was varied. From the reaction mixtures, $10 \mu \mathrm{L}$ was withdrawn periodically and dissolved in $90 \mu \mathrm{L}$ of acetone, and then diluted 10 times with methanol and subjected to HPLC analysis after centrifugation.

High-Pressure Liquid Chromatography (HPLC). DHCA and relative ester products were analyzed by a HPLC system equipped with PDA detector and RP C18 column $(250 \times 4.6$ $\mathrm{mm}, 5 \mu \mathrm{m}$ ) from Thermo Scientific (Waltham, MA) in the range of $210-280 \mathrm{~nm}$. Tricaprylin was detected by an evaporative light scattering detector (ELSD; SEDEX MODEL 80, France) using an evaporation temperature of $30^{\circ} \mathrm{C}$. Injection of $10 \mu \mathrm{L}$ was eluted from the column at a flow rate of $1 \mathrm{~mL} / \mathrm{min}$ using a binary solvent system, which was composed of $90 \%$ solvent A (methanol) and 10\% solvent B (0.75\% acetic acid in Milli-Q water) and developed for $16 \mathrm{~min}$.

HPLC-ESI-MS Analysis. HPLC-ESI-MS analyses were performed on samples prepared for HPLC analysis. Elution conditions, column, as well as solvents used in mobile phase were identical to those described previously for HPLC. Mass spectral reaction products were analyzed using an electrospray ionization (ESI) source coupled to a quadrupole time-of-flight mass spectrometer (Bruker micrOTOF-Q, Bremen, Germany). Ionization was performed in the negative mode with an $8 \mathrm{~L} / \mathrm{min}$ nitrogen flow, 0.8 bar nebulizer pressure, and a temperature of $190{ }^{\circ} \mathrm{C}$. Scan range was from 50 to $1200 \mathrm{~m} / z$.

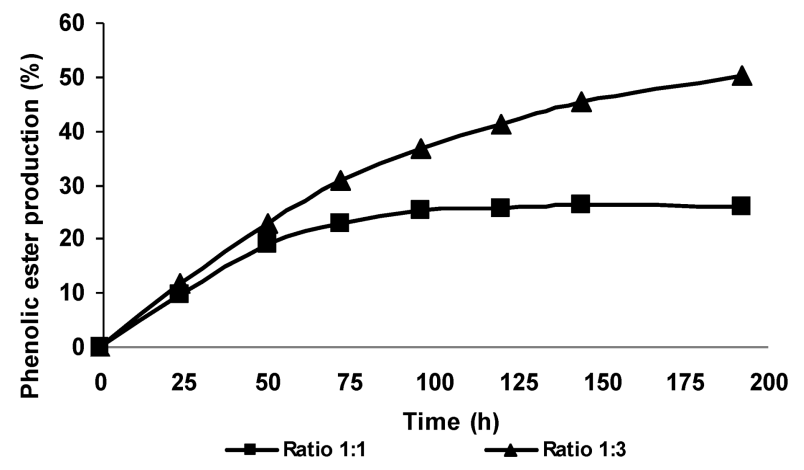

Figure 1. Ester production from DHCA and octanol during $192 \mathrm{~h}(10 \%$ enzyme, $60^{\circ} \mathrm{C}$ ).

Experimental Design and Statistical Analyses. Experiments were conducted using a central composite rotatable design (CCRD) to investigate the linear, quadratic, and cross-product effects of three factors, varying the amount of enzyme $(1.6-18.4 \%)$, reaction time $(9.9-35.1 \mathrm{~h})$, and temperature $\left(43.2-76.8^{\circ} \mathrm{C}\right)$. The response evaluated was the percentage of reagents consumed, which was verified by the areas obtained by HPLC. The ranges chosen were based on different papers with the same enzyme. ${ }^{9,15-18}$

A software package (Modde 6.0, Umetri, Umeå, Sweden) was used to fit the second-order model to the independent variables.

\section{RESULTS AND DISCUSSION}

Ester Production. Ester (octyl dihydrocaffeate) production in two different molar ratios is presented in Figure 1.

The substrate molar ratio 1:3 was the best for ester production and reached $50 \%$ in $192 \mathrm{~h}$ ( 8 days of reaction). An excess of octanol may have altered the solubility, hence favoring higher production of phenolic lipids, shifting the balance toward the formation of more product (ester), increasing the reaction rate. However, at 1:1 ratio, ester production remained constant (up to $26 \%)$, reaching the reaction equilibrium after $96 \mathrm{~h}$.

Cassani et al. ${ }^{12}$ verified that the number and nature of substituents on the aromatic ring (as methyl and hydroxyl groups) have a strong influence over lipase catalytic behavior, reflecting on the time needed to reach equilibrium and the final conversion of the esterification of phenylpropanoids acids, which is the case of caffeic acid. Karboune et al. ${ }^{19}$ and Lue et al. ${ }^{20}$ reported lipase-catalyzed esterification of cinnamic acid with oleoyl alcohol and mono- and diacylated glycerols in several solvent mixtures. In both cases, the equilibrium was achieved after long periods of reaction, more than 5 days. Sabally et al. ${ }^{7}$ observed a significant improvement in the reaction time (equilibrium time $<3$ days), when dihydrocaffeic acid and flaxseed oil were used as substrates. The authors used different solvent system composition (e.g., hexane:2-butanone in three different ratios such as $65: 35,75: 25$, and 85:15). Novozym 435 is known to be more efficient in hydrophobic reactions. Hexane provides a hydrophobic environment, and butanone increases the solubility of DHCA. The conversion increases when more hexane and less butanone are added to the system. Therefore, the use of tert-butanol in the present work affected the reaction, increasing catalysis time.

Macedo, Lozano, and Pastore ${ }^{21}$ produced citronellyl esters (butyrate) in only $24 \mathrm{~h}$ using lipase from Rhizopus sp, obtaining a 

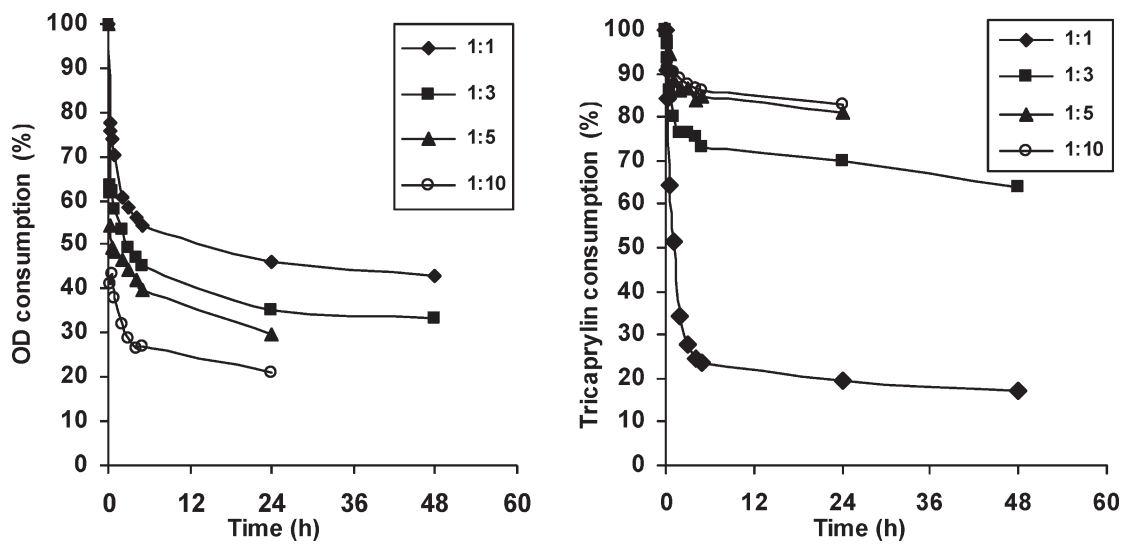

Figure 2. OD:tricaprylin consumption at 1:1, 1:3, 1:5, and 1:10 molar ratios.

Table 1. Coded Levels (in Parentheses), Real Values for CCDR, and Results of Substrates Consumption for Octyl Dihydrocaffeate and Tricaprylin in Transesterification Reactions ${ }^{a}$

\begin{tabular}{|c|c|c|c|c|c|c|c|}
\hline assay & $X_{1}$ & $X_{2}$ & $X_{3}$ & $Y_{1}(\%)$ & PV $Y_{1}(\%)$ & $Y_{2}(\%)$ & $\mathrm{PV} Y_{2}(\%)$ \\
\hline 1 & $5(-1)$ & $50(-1)$ & $15.0(-1)$ & 33.85 & 37.45 & 71.14 & 71.93 \\
\hline 2 & $15(+1)$ & $50(-1)$ & $15.0(-1)$ & 24.92 & 23.93 & 68.51 & 68.6 \\
\hline 3 & $5(-1)$ & $70(+1)$ & $15.0(-1)$ & 21.89 & 26.6 & 74.06 & 72.66 \\
\hline 4 & $15(+1)$ & $70(+1)$ & $15.0(-1)$ & 19.25 & 19.3 & 73.2 & 73.5 \\
\hline 5 & $5(-1)$ & $50(-1)$ & $30.0(+1)$ & 29.22 & 33.14 & 70.19 & 69.82 \\
\hline 6 & $15(+1)$ & $50(-1)$ & $30.0(+1)$ & 23.2 & 22.46 & 63.24 & 64.57 \\
\hline 7 & $5(-1)$ & $70(+1)$ & $30.0(+1)$ & 18.19 & 23.15 & 72.92 & 72.76 \\
\hline 8 & $15(+1)$ & $70(+1)$ & $30.0(+1)$ & 18.33 & 18.7 & 72.54 & 71.68 \\
\hline 9 & $1.6(-\alpha)$ & $60(0)$ & $22.5(0)$ & 50.87 & 42.56 & 73.87 & 74.51 \\
\hline 10 & $18.4(+\alpha)$ & $60(0)$ & $22.5(0)$ & 24.75 & 27.44 & 71.35 & 70.8 \\
\hline 11 & $10(0)$ & $43.2(-\alpha)$ & $22.5(0)$ & 29.08 & 25.08 & 67.13 & 65.23 \\
\hline 12 & $10(0)$ & $76.8(+\alpha)$ & $22.5(0)$ & 19.34 & 15.26 & 71.39 & 72.61 \\
\hline 13 & $10(0)$ & $60(0)$ & $9.9(-\alpha)$ & 24.63 & 22.17 & 70.86 & 70.94 \\
\hline 14 & $10(0)$ & $60(0)$ & $35.1(+\alpha)$ & 21.19 & 18.05 & 67.64 & 67.64 \\
\hline 15 & $10(0)$ & $60(0)$ & $22.5(0)$ & 21.35 & 24.05 & 67.02 & 65.98 \\
\hline 16 & $10(0)$ & $60(0)$ & $22.5(0)$ & 25.25 & 24.05 & 65.47 & 65.98 \\
\hline 17 & $10(0)$ & $60(0)$ & $22.5(0)$ & 24.59 & 24.05 & 65.46 & 65.98 \\
\hline
\end{tabular}

${ }^{a} X_{1}=$ enzyme load (\%), based on total substrates; $X_{2}=$ temperature $\left({ }^{\circ} \mathrm{C}\right) ; X_{3}=$ time $(\mathrm{h}) ; Y_{1}$, octyl dihydrocaffeate; $Y_{2}$, tricaprylin; PV, predicted value by the model.

yield of $95-100 \%$ with or without $n$-hexane. Citronellyl acetate was synthesized by transesterification with ethyl acetate and citronellol, with a yield of $58 \%$ after $48 \mathrm{~h}$ and $48 \%$ conversion for acetate and citronellol reaction. The results suggest that the size of the aliphatic chain of acyl donor was important for conversion rate. In the present study, octanol (acyl donor) has eight carbons, which may have influenced the low conversion obtained (50\%) in a longer period of time when compared to the previously mentioned authors who used 4 carbon-alcohol, resulting in a higher conversion yield in less time.

Yang et al. ${ }^{22}$ reported that reacting sunflower oil with glycerol catalyzed by lipase (Novozym 435) in a tert-butanol system was very useful in batch reactors, once it favored the synthesis of monoesters, producing $70 \%$ of monoacylglycerols, with the equilibrium being achieved in $2 \mathrm{~h}$. Reactions conducted in packed bed reactors with oil rich in conjugated linoleic acid and glycerol originated a similar yield of monoacylglycerols, but in a shorter time $(30 \mathrm{~min})$. tert-Butanol is particularly effective for relatively
Table 2. ANOVA Table for Octyl Dihydrocaffeate Consumption $^{a}$

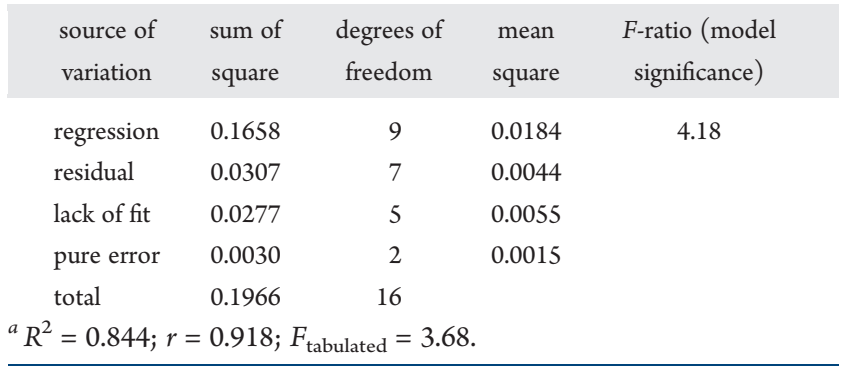

hydrophilic substrates, ${ }^{1}$ besides being a good solvent for flavonoid esterification due to the high solubility of phenolic compounds. ${ }^{23}$

Transesterification. Figure 2 shows the curves of octyl dihydrocaffeate and tricaprylin consumption along the time at four different molar ratios. The percentages were calculated by peak 
area obtained by HPLC, which were monitored in time intervals. Tricaprylin was the triacylglycerol used for acyl group donation to

Table 3. ANOVA Table for Tricaprylin Consumption ${ }^{a}$

$\begin{array}{crcrc}\begin{array}{c}\text { source of } \\ \text { variation }\end{array} & \begin{array}{r}\text { sum of } \\ \text { square }\end{array} & \begin{array}{c}\text { degrees of } \\ \text { freedom }\end{array} & \begin{array}{c}\text { mean } \\ \text { square }\end{array} & \begin{array}{c}\text { F-ratio (model } \\ \text { significance) }\end{array} \\ \text { regression } & 162.91 & 9 & 18.10 & 12.2 \\ \text { residual } & 10.41 & 7 & 1.48 & \\ \text { lack of fit } & 8.80 & 5 & 1.76 & \\ \text { pure error } & 1.61 & 2 & 0.80 & \\ \text { total } & 173.32 & 16 & & \\ { }^{a} R^{2}=0.937 ; r=0.968 ; F_{\text {tabulated }}=3.68 .\end{array}$

produce phenolic lipids, and octyl dihydrocaffeate was the limiting substrate, with the graph discussed being based on the last one.

OD to tricaprylin molar ratios varied from $1: 1$ to $1: 10$. A maximum conversion of $78.9 \%$ was observed in $24 \mathrm{~h}$ at $1: 10$ molar ratio. Thus, $21.1 \%$ of unreacted OD was still present according to the graph in Figure 2. At 1:5 molar ratio, $70.4 \%$ of conversion was achieved (29.6\% unreacted OD) at the same time. The lowest conversions were obtained at $1: 1$ and $1: 3$ ratios, either with 24 or $48 \mathrm{~h}$ reaction time.

The reactions at 1:5 and 1:10 were stopped at $24 \mathrm{~h}$, because there was no significant increase in conversion at $1: 1$ and $1: 3$ when comparing $24 \mathrm{~h}$ with $48 \mathrm{~h}$ reaction. Thus, reactions tended to reach equilibrium after $24 \mathrm{~h}$. Oliveira et al. ${ }^{17}$ found a conversion of $73 \%$ through alcoholysis reaction using the same enzyme

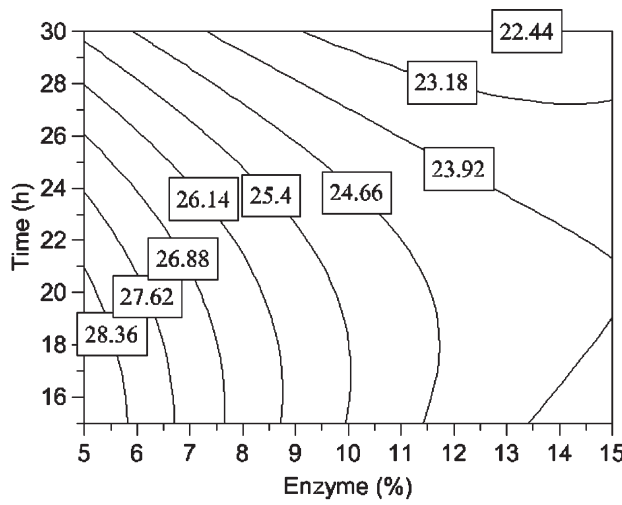

(a)

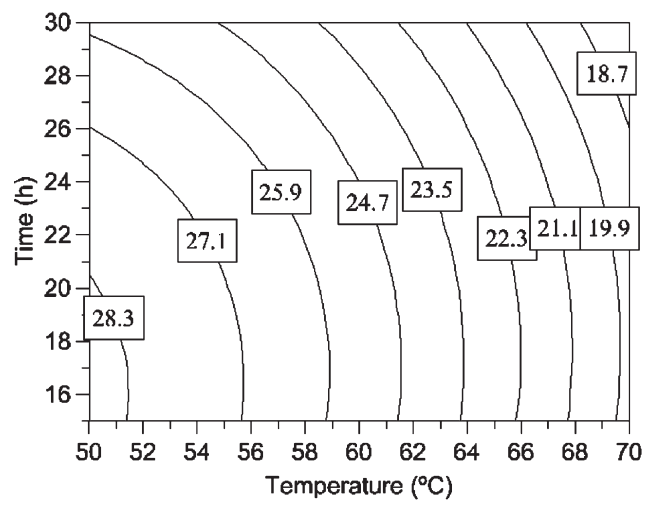

(c)

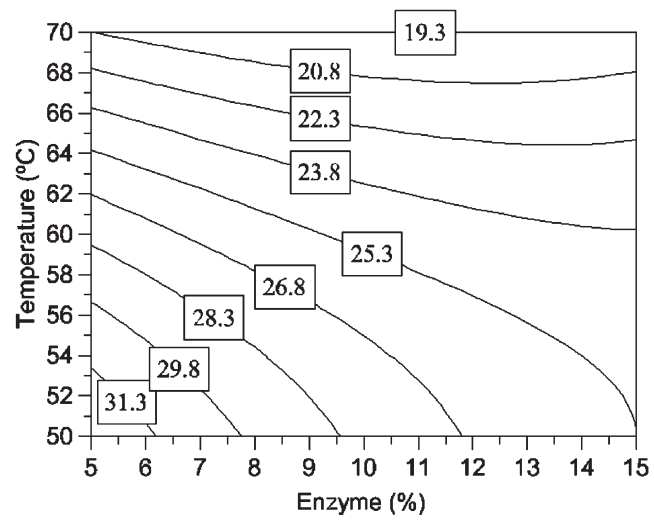

(e)

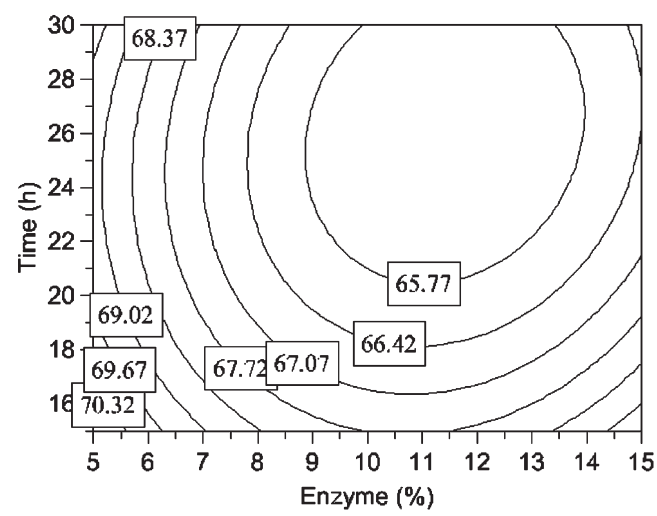

(b)

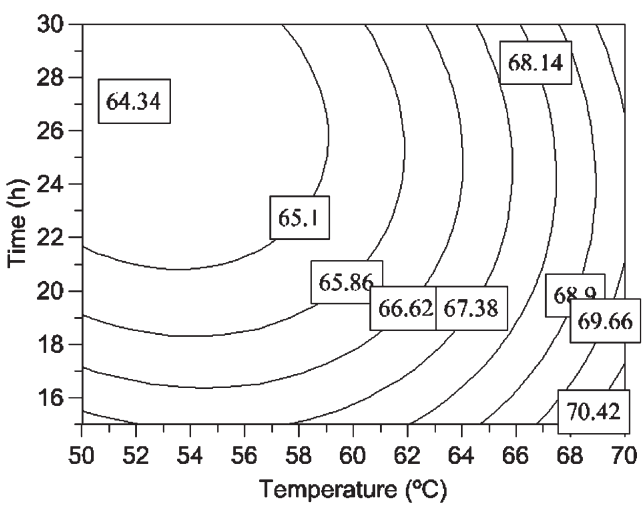

(d)

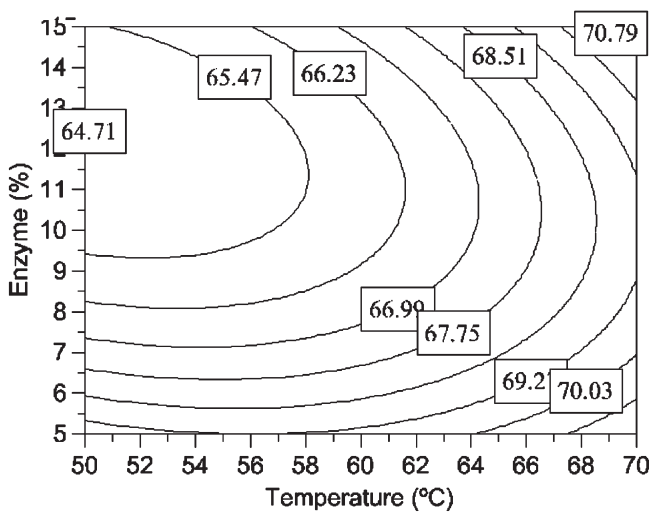

(f)

Figure 3. Contour plots of octyl dihydrocaffeate $(\mathrm{a}, \mathrm{c}, \mathrm{e})$ and tricaprylin $(\mathrm{b}, \mathrm{d}, \mathrm{f})$ consumption in transesterification reactions. 


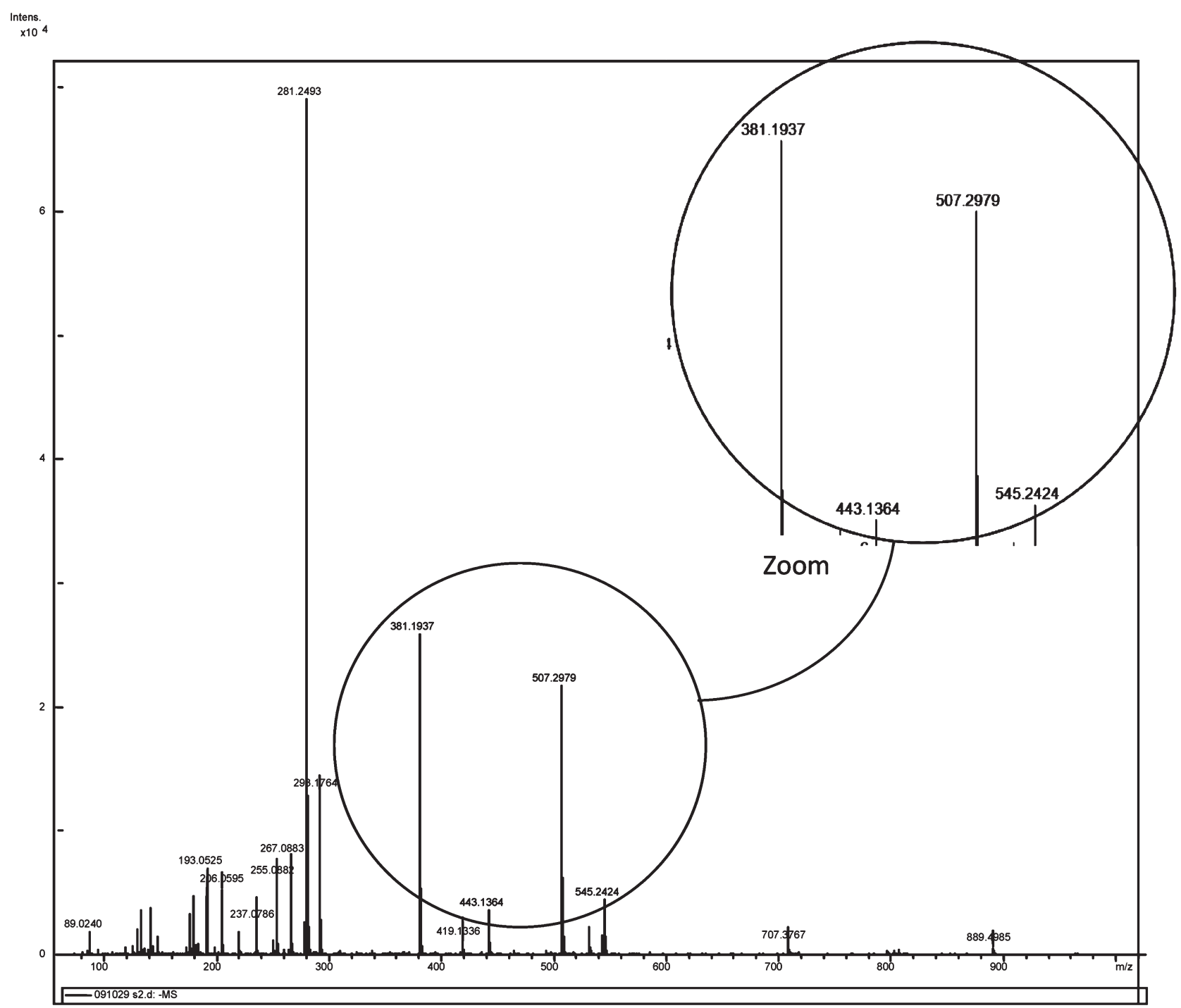

Figure 4. Mass spectrum of the interesterified products.

(Novozym 435) at $1: 10$ substrate ratio, $10 \%$ water, and $20 \%$ enzyme concentration.

Table 1 shows the experimental design conditions and the results for consumption (\%) of both substrates octyl dihydrocaffeate $(\mathrm{OD})$ and tricaprylin at 1:5 molar ratio. Table 1 also shows the predicted values by the model. The lowest responses indicate the higher consumption of substrates.

According to Table 1, temperature affected OD consumption more than did reaction time and enzyme load. Lower $Y_{1}$ values in transesterification reactions reflected more substrate consumption, that is, more conversion into products. For example, assays 4, 7, 8, and 12 showed the lowest $Y_{1}$ values $(18.19-19.34 \%)$. In all of these reactions, temperatures were above $70^{\circ} \mathrm{C}$, while reaction time and enzyme load ranged from 15 to $30 \mathrm{~h}$ and $5 \%$ to $15 \%$, respectively.

In Table $1, Y_{2}$ values were affected by low temperatures $\left(50-60{ }^{\circ} \mathrm{C}\right)$, higher enzyme load $(10-15 \%)$, and reaction time $(22.5-30 \mathrm{~h})$. This can be observed through $Y_{2}$ values in assays 6, 16, and 17, which presented the lower consumption (63.24-54.47\%).

Data regarding transesterification reactions with phenolic lipids are quite scarce in the literature. Yang et al. ${ }^{14}$ established a protocol for enzymatic synthesis of dihydrocaffoylated glycerides with OD as a synthetic intermediate using Novozym 435 lipase. The optimized reaction conditions were generated through RSM, with the values being obtained as follows: $65.2-70{ }^{\circ} \mathrm{C}, 24.25-43.6 \mathrm{~h}$, and $14.6-19.9 \%$.

Tables 2 and 3 show the analysis of variance (ANOVA) for octyl dihydrocaffeate (OD) and tricaprylin consumption. ANOVA was used to evaluate the adequacy of the fitted model. OD data were normalized by employing logarithmic transformation to consumption data to fit the model.

Second-order models were established on the basis of ANOVA, as shown in Tables 2 and 3. The models describe the substrates consumption as a function of enzyme load, temperature, and reaction time and are expressed in eqs 1 and 2, where $X_{1}=$ enzyme load (\%), $X_{2}=$ temperature $\left({ }^{\circ} \mathrm{C}\right)$, and $X_{3}=$ reaction time $(\mathrm{h})$.

octyl dihydrocaffeate $=54.7403-6.2905 x_{1}+0.3808 x_{2}$

$$
\begin{aligned}
& +0.5896 x_{3}+0.1548 x_{1}^{2}-9.35 \\
& \times 10^{-3} x_{2}^{2}-2.48 \times 10^{-2} x_{3}^{2} \\
& +0.0311 x_{1} x_{2}+0.0190 x_{1} x_{3} \\
& +2.88 \times 10^{-3} x_{2} x_{3}
\end{aligned}
$$




\section{Scheme 1. Esterification and Transesterification Reactions ${ }^{a}$}

\section{Esterification reaction}

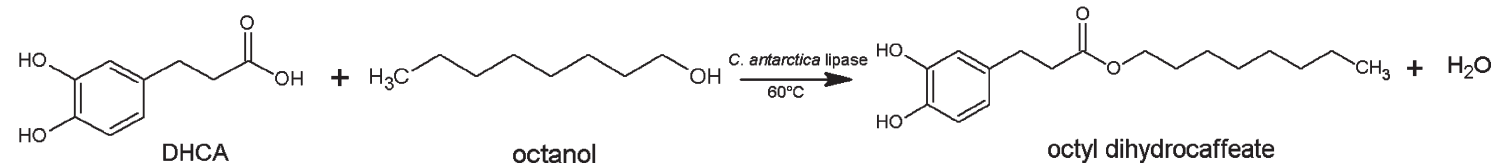<smiles>CCCCCCCC(=O)OCC(COC(=O)CCCCCCC)OC(=O)CCCCCCC</smiles>

${ }^{a}$ Possible products from transesterification reactions: (A) 1(3)-octyl dihydrocaffeate-2-monocaprylin-3(1)-hydroxyl; (B) 1(3)-octyl dihydrocaffeate2,3(1,2)-dicaprylin; and (C) 1,2(2,3)-octyl dihydrocaffeate-1(3)-monocaprylin.

$$
\begin{aligned}
\text { tricaprylin }= & 141.3302-3.0727 x_{1}-1.5909 x_{2}-1.3842 x_{3} \\
& +0.0945 x_{1}^{2}+0.0118 x_{2}^{2}+0.0209 x_{3}^{2} \\
& +0.0208 x_{1} x_{2}-0.0128 x_{1} x_{3}+0.0074 x_{2} x_{3}
\end{aligned}
$$

The pure error was very low, indicating a good reproducibility of the experimental data. On the basis of the $F$ test, the model is predictive, because its calculated $F$ value is higher than the critical $F$ value and the regression coefficient is close to unity. The coded model was used to generate contour plots (Figure 3) for the analysis of the variable effects on both esters consumption. They are useful to explain the interaction of the variables and to determine the optimum level of each variable for maximum response. Each graphic demonstrates the effect of two factors, while the other ones were fixed at zero level.

Higher enzyme concentrations will catalyze the substrates leading to products' synthesis. Figure 3 a shows that more than $26 \mathrm{~h}$ and $10 \%$ enzyme were necessary to obtain the lowest value of unreacted octyl dihydrocaffeate $(22.4 \%)$; that is, the conversion obtained was around $80 \%$. According to Figure $3 \mathrm{c}$, the higher was the temperature $\left(67.5-70{ }^{\circ} \mathrm{C}\right)$, the lower was the unreacted octyl dihydrocaffeate $(18.7 \%)$ in the reaction system. Figure $3 \mathrm{e}$ confirms the previous observations.

For tricaprylin substrate, the lowest value was obtained using approximately $9-13 \%$ enzyme (Figure $3 b$ and $f$ ) in at least $22 \mathrm{~h}$ (Figure $3 \mathrm{~b}$ and $\mathrm{d}$ ), but at temperatures below $58^{\circ} \mathrm{C}$ (Figure $3 \mathrm{~d}$ and $\mathrm{f}$ ). In this case, it is the opposite of the required temperature for the phenolic substrate.
According to Prabhavathi-Devi, Guo, and $\mathrm{Xu},{ }^{24}$ Novozym 435 immobilized lipase attains its maximum activity at $70{ }^{\circ} \mathrm{C}$, as observed in the present work. The same authors emphasized the importance of controlling temperature, which affects both the reaction rate and the solubility of different substrates. Although it is suggested that this enzyme should be used at $40-60{ }^{\circ} \mathrm{C}$ for the sake of its stability, Xin et al. ${ }^{25}$ reported that Novozym 435 may be used nine times without significant loss of activity at $60{ }^{\circ} \mathrm{C}$ in transesterification reaction to synthesize ferulyl oleins. Sun et al. $^{26}$ synthesized feruloylated diacylglycerols using lipase in a solvent-free system. The optimum conditions were as follows: temperature $\left(65^{\circ} \mathrm{C}\right)$, enzyme load $(7.5 \%)$, substrate ratio (7.5:1 oleic acid to glyceryl ferulate+glycerol), and reaction time $(12 \mathrm{~h})$. In these conditions, a yield of glyceryl ferulate and feruloylated diacylglycerols of, respectively, $98.0 \%$ and $82.6 \%$ was obtained.

Products Identified by HPLC-ESI-MS. The fragmentation patterns of the main interesterified phenolic products from octyl dihydrocaffeate and tricaprylin reaction are presented in Figure 4, where three major peaks were detected, which represent di- and triacylglycerol products.

According to Figure 4, the first abundant peak identified was 1(3)-octyl dihydrocaffeate-2-monocaprylin-3(1)-hydroxyl, showing a molecular ion of $m / z 381[\mathrm{M}-\mathrm{H}]^{-}$. Analysis of the second most abundant peak indicated it was 1(3)-octyl dihydrocaffeate 2,3(1,2)-dicaprylin at $\mathrm{m} / z 507[\mathrm{M}-\mathrm{H}]^{-}$. The third one was identified as 1,2(2,3)-octyl dihydrocaffeate-1(3)-monocaprylin with a molecular ion of $m / z 545[\mathrm{M}-\mathrm{H}]^{-}$. 
Scheme 1 shows the esterification reaction catalyzed by lipase in tert-butanol as well as the transesterification reaction between the phenolic ester (octyl dihydrocaffeate) and tricaprylin. As the regioselectivity of the reaction is unknown, possible products (A, B, C) are also shown including the products' position probability of the substituent groups in the glycerol molecule.

As a nonspecific lipase (Novozym 435) was used, the regioselectivity of the products (A, B, and C in Scheme 1) is unknown; that is, the probability of formation of various possibilities of products was expected, because this enzyme catalyzes the hydrolysis of triacylglycerols in any position.

The new modified lipids obtained are likely to have UV radiation protection as well as emulsifying capacity. Ultraviolet radiation absorption depends on the electronic structure of a given molecule. Cinnamic acids and derivatives have aromatic groups (chromophore groups) capable of absorbing UV radiation that promotes resistance to potential skin damage. ${ }^{27}$ The introduction of aromatic groups, which is the case of the OD compound (Scheme 1), into structured lipid is most likely to increase protection against $\mathrm{UV}$ rays. Thus, compound $\mathrm{C}$ in Scheme 1 probably has more potential as UV protector than do the other two (A and $B$ ).

A higher emulsifying capacity is expected with the new structured lipids when compared to the original TAG, because their molecular structures have both hydrophobic (linear carbon chain) and hydrophilic (phenolic) groups, which allow higher activity in the oil-water interface.

\section{CONCLUSIONS}

It was found that fungal lipase (Novozym 435) catalyzed the highest ester yield from DHCA to octanol (1:3) in up to $50 \%$ over 8 days. In transesterification reactions, the molar ratios that presented higher octyl dihydrocaffeate conversion were at 1:5 (70.4\%) and 1:10 (78.9\%), obtaining, respectively, $29.6 \%$ and $21.1 \%$ of octyl dihydrocaffeate residual, in $24 \mathrm{~h}$. It was observed that at high temperatures and time above $26 \mathrm{~h}$, there was less octyl dihydrocaffeate residual (18.7\%), that is, higher conversion. It is therefore suggested the addition of $10 \%$ enzyme, $26 \mathrm{~h}$ reaction time, and temperature of $70{ }^{\circ} \mathrm{C}$ for maximum production of phenolic compounds. Three different phenolic compounds containing in their molecular structure octyl dihydrocaffeate and caprylic acid were identified. These new structured lipids are likely to have both emulsifying activity and UV protection.

\section{AUTHOR INFORMATION}

\section{Corresponding Author}

*E-mail: vfeddern@yahoo.com.br.

\section{ACKNOWLEDGMENT}

We thank the Agro-biotechnology group (University of Aarhus) where the work was developed and CAPES/PDEE for a scholarship (process number 1104-09-8) given to V.F.

\section{REFERENCES}

(1) Stevenson, D. E.; Parkar, S. G.; Zhang, J.; Stanley, R. A.; Jensen, D. J.; Cooney, J. M. Combinatorial enzymic synthesis for functional testing of phenolic acid esters catalysed by Candida antarctica lipase B (Novozym 435). Enzyme Microb. Technol. 2007, 40, 1078.

(2) Gugliucci, A.; Bastos, D. H. M.; Schulze, J.; Souza, M. F. F. Caffeic and chlorogenic acids in Ilex paraguariensis extracts are the main inhibitors of AGE generation by methylglyoxal in model proteins. Fitoterapia 2009, 80, 339.

(3) Figueroa-Espinoza, M. C.; Villeneuve, P. Phenolic acids enzymatic lipophilization. J. Agric. Food Chem. 2005, 53, 2779.

(4) Huang, J.; Paulis, T.; May, J. M. Antioxidant effects of dihydrocaffeic acid in human EA.hy926 endothelial cells. J. Nutr. Biochem. 2004, 15,722 .

(5) Stamatis, H.; Sereti, V.; Kolisis, F. N. Enzymatic synthesis of hydrophilic and hydrophobic derivatives of natural phenolic acids in organic media. J. Mol. Catal. B: Enzym. 2001, 11, 323.

(6) Silva, F. A. M.; Borges, F.; Guimarães, C.; Lima, J. L. F. C.; Matos, C.; Reis, S. Phenolic acids and derivatives: studies on the relationship among structure, radical scavenging activity, and physicochemical parameters. J. Agric. Food Chem. 2000, 48, 2122.

(7) Sabally, K.; Karboune, S.; St-Louis, R; Kermasha, S. Lipasecatalyzed transesterification of dihydrocaffeic acid with flaxseed oil for the synthesis of phenolic lipids. J. Biotechnol. 2006, 127, 167.

(8) Sabally, K.; Karboune, S.; St-Louis, R; Kermasha, S. Lipasecatalyzed synthesis of phenolic lipids from fish liver oil and dihydrocaffeic acid. Biocatal. Biotransform. 2007, 25, 211.

(9) Kahveci, D.; Guo, Z.; Özçelik, B.; Xu, X. Lipase-catalyzed glycerolysis in ionic liquids directed towards diglyceride synthesis. Process Biochem. 2009, 44, 1358.

(10) Devi, B. L. A. P.; Zhang, H.; Damstrup, M. L.; Guo, Z.; Zhang, L.; Lue, B.-M.; Xu, X. Enzymatic synthesis of designer lipids. OCL-Ol. Corps Gras Li. 2008, 15, 189.

(11) Otto, R. T.; Scheib, H.; Bornscheuer, U. T.; Pleiss, J.; Syldatk, C.; Schmid, R. D. Substrate specificity of lipase B from Candida antarctica in the synthesis of arylaliphatic glycolipids. J. Mol. Catal. B: Enzym. 2000, 8, 201.

(12) Cassani, J.; Luna, H.; Navarro, A.; Castillo, E. Comparative esterification of phenylpropanoids versus hydrophenylpropanoids acids catalyzed by lipase in organic solvent media. Electron. J. Biotechnol. 2007, 10,508 .

(13) Lee, K. T.; Akoh, C. C. Characterization of enzymatically synthesized structured lipids containing eicosapentaenoic, docosahexaenoic, and caprylic acids. J. Am. Oil Chem. Soc. 1998, 75, 495.

(14) Yang, Z.; Feddern, V.; Glasius, M.; Guo, Z.; Xu, X. Improved enzymatic production of phenolated acylglycerols through alkyl phenolate intermediates. Biotechnol. Lett. 2011, 33, 673.

(15) Brusamarelo, C. Z.; Rosset, E.; Césaro, A.; Treichel, H.; Oliveira, D.; Mazutti, M. A.; Di Luccio, M.; Oliveira, J. V. Kinetics of lipase-catalyzed synthesis of soybean fatty acid ethyl esters in pressurized propane. J. Biotechnol. 2010, 147, 108.

(16) Sun, S.; Shan, L.; Liu, Y.; Jin, Q.; Song, Y.; Wang, X. Solvent-free enzymatic synthesis of feruloylated diacylglycerols and kinetic study. J. Mol. Catal. B: Enzym. 2009, 57, 104.

(17) Oliveira, D.; Luccio, M.; Di ; Faccio, C.; Rosa, C. D.; Bender, J. P.; Lipke, N.; Menoncin, S.; Amroginski, C.; Oliveira, J. V. Optimization of enzymatic production of biodiesel from castor oil in organic solvent medium. Appl. Biochem. Biotechnol. 2004, 115, 771.

(18) Oliveira, D.; Alves, T. L. M. A kinetic study of lipase catalyzed alcoholysis of palm kernel oil. Appl. Biochem. Biotechnol. 2000, $84-86,59$.

(19) Karboune, S.; Safari, M.; Lue, B.-M.; Yeboah, F. K.; Kermasha, $\mathrm{S}$. Lipase-catalyzed biosynthesis of cinnamoylated lipids in a selected organic solvent medium. J. Biotechnol. 2005, 119, 281.

(20) Lue, B.-M.; Karboune, S.; Yeboah, F. K.; Kermasha, S. Lipase-catalyzed esterification of cinnamic acid and oleyl alcohol in organic solvent media. J. Chem. Technol. Biotechnol. 2005, 80, 462.

(21) Macedo, G. A.; Lozano, M. M. S.; Pastore, G. M. Enzymatic synthesis of short chain citronellyl esters by a new lipase from Rhizopus sp. Electron. J. Biotechnol. 2003, 6, 72. 
(22) Yang, T.; Rebsdorf, M.; Engelrud, U.; Xu, X. Monoacylglycerol synthesis via enzymatic glycerolysis in an efficient reaction system. J. Food Lipids 2005, 12, 299.

(23) Hu, Y.; Guo, Z.; Lue, B.-M.; Xu, X. Enzymatic synthesis of lipophilic flavonoid derivatives in ionic liquids buffered with organic solvents. J. Agric. Food Chem. 2009, 57, 3845.

(24) Prabhavathi Devi, B. L. A.; Guo, Z.; Xu, X. Characterization of cross-linked lipase aggregates. J. Am. Oil Chem. Soc. 2009, 86, 637.

(25) Xin, J.-y.; Zhang, L.; Chen, L.-1.; Zheng, Y.; Wu, X.-m.; Xia, C.-g. Lipase-catalyzed synthesis of ferulyl oleins in solvent-free medium. Food Chem. 2009, 112, 640.

(26) Sun, S.; Shan, L.; Liu, Y.; Jin, Q.; Song, Y.; Wang, X. Solvent-free enzymatic synthesis of feruloylated diacylglycerols and kinetic study. J. Mol. Catal. B: Enzym. 2009, 57, 104.

(27) Edreva, A. The importance of non-photosynthetic pigments and cinnamic acid derivatives in photoprotection. Agric. Ecosyst. Environ. 2005, 106, 135. 